\title{
Determination of Sulfur Compounds in Hydrotreated Transformer Base Oil by Potentiometric Titration
}

\author{
Qiu Chao,* Han Sheng, ${ }^{*}$ Xingguo Cheng, ${ }^{* *}$ and Tianhui ReN*广 \\ * School of Chemistry and Chemical Technology, Shanghai Jiao Tong University, \\ 800 Dongchuan Road, Shanghai 200240, P. R. China \\ **Lanzhou Lube Oil R\&D Institute of Petrochina, 369 Yumen Street, Lanzhou 730060, P. R. China
}

\begin{abstract}
A method was developed to analyze the distribution of sulfur compounds in model sulfur compounds by potentiometric titration, and applied to analyze hydrotreated transformer base oil. Model thioethers were oxidized to corresponding sulfoxides by tetrabutylammonium periodate and sodium metaperiodate, respectively, and the sulfoxides were titrated by perchloric acid titrant in acetic anhydride. The contents of aliphatic thioethers and total thioethers were then determined from that of sulfoxides in solution. The method was applied to determine the organic sulfur compounds in hydrotreated transformer base oil.
\end{abstract}

(Received December 10, 2004; Accepted January 17, 2005)

\section{Introduction}

In general, transformer oil is a product of petroleum refining and a complex mixture of paraffin, naphthene and aromatic compounds. Small amounts of derivatives of hydrocarbons that include atoms of other elements, such as nitrogen, sulfur, and oxygen, also enter into the composition of transformer oil. The oxidation stability of transformer oil is one of main performances, and it is of great concern by transformer oil manufacturers and consumers. There are many factors that affect the oxidation stability, including oil composition, storage and service. In particular, it is greatly affected by the amounts and composition of the sulfur compounds in oil.

Sulfur compounds can improve the oxidation stability of lubricating oil, and some of them are considered to be natural antioxidants. ${ }^{1-3}$ Even though some sulfur compounds can improve the oxidation stability of oil, not all sulfur compounds have favorable effects. There are corrosive and non-corrosive sulfur compounds in base oil, for example mercaptans, thioethers, thiophenes and disulfides. The oxidation resistance of sulfur compound is different for different molecular structures. ${ }^{4}$ Since these days transformer base oil is mostly hydrotreated, there are only small amount of mercaptans and disulfides. As a result, it is necessary to clarify the distribution of thioethers and thiophenes to improve the oxidation stability in base oil.

Chemical and instrumental methods were emphasized concerning oxidative approaches for thioether analysis. A microchemical method based on bromine oxidation was described by Belcher and co-workers. Direct titration on small samples (about $50 \mu \mathrm{g}$ ) was accomplished by employing 0.02 mol dm${ }^{-3} \mathrm{KBrO}_{3}$. However, some problems with overoxidation were also reported. ${ }^{5}$ The oxidation of thioethers with hypochlorite was reported by Leutch. This method employed a

$\doteqdot$ To whom correspondence should be addressed.

E-mail: thren@sjtu.edu.cn
$0.1 \mathrm{~mol} \mathrm{dm}^{-3}$ sodium hypochlorite solution, but a more dilute hypochlorite solution was found to rapidly deteriorate. Thus, difficulties were encountered when adapting the method to the micro scale. ${ }^{6}$ D'Alonzo reported that organic thioethers were oxidized to the corresponding sulfoxides using aqueous sodium metaperiodate. Simultaneously, the periodate was reduced to iodate, which could be quantitatively precipitated by the addition of silver ion in nitric acid. The precipitate was filtered and dissolved in ammonium hydroxide, and the resulting solution was analyzed for its silver content by atomicabsorption spectrometry. ${ }^{7}$ Puchalsky described a method for the analysis of organic thioethers by titration of their hydrogen peroxide-formed sulfoxides. Thioethers were treated with hydrogen peroxide in acetic acid at room temperature to produce the corresponding sulfoxides. Subsequent potentiometric titration of the formed sulfoxide derivative in acetic anhydride was accomplished using $\mathrm{HClO}_{4}$. The oxidation conditions were hard to control. If the oxidation time and temperature were not suitable, hydrogen peroxide could oxidize thioethers to sulfones, and the result was not accurate. ${ }^{8}$

The goal of the experiment was to develop a simple method for the determination of organic aliphatic thioethers, total thioethers with high selectivity; it was then applied to analyze hydrotreated transformer base oil obtained from Kelamayi Petro-chemical Corporation (Xinjiang, China); the contents of mercaptans and disulfides were too low to be measured in our previous experiment.

\section{Experimental}

\section{The principle of the experiment}

Sulfoxides present measurable basicity, and can be titrated in acetic anhydride. Thioethers are oxidized to sulfoxides by periodate, and the concentration of sulfoxides is determined by potentiometric titration. The content of thioethers is obtained from the following equation: 
Table 1 Concentration of each sulfur compound in a sulfur compounds solution

\begin{tabular}{lcc}
\hline \multicolumn{1}{c}{ Sulfur compound } & Weight/mg & Concentration of S/ $\mu \mathrm{g} \mathrm{g}^{-1}$ \\
\hline Butyl thioether & 115.7 & 126.80 \\
Dodecyl thioether & 216.3 & 93.55 \\
Ethyl phenyl thioether & 63.7 & 73.88 \\
Phenyl thioether & 144.8 & 124.63 \\
Dibenzothiophene & 144.5 & 125.74 \\
\hline
\end{tabular}

$$
\mathrm{RSR}^{\prime}+\mathrm{IO}_{4}^{-} \longrightarrow \mathrm{RSOR}^{\prime}+\mathrm{IO}_{3}^{-}
$$

\section{Apparatus}

A Metrohm 796 titraprocessor, fitted with glass and saturated calomel electrodes, was used to plot the titration curves of the sulfoxides.

\section{Reagents}

$n$-Butyl thioether, $n$-dodecyl thioether, ethyl phenyl thioether, phenyl thioether and dibenzothiophene were all purchased from TCI. All sulfur compounds were of the purest grades available. Model sulfur compounds were accurately weighted and dissolved in $200 \mathrm{~g}$ of ethylbenzene. Table 1 gives the concentration of sulfur of each sulfur compound in solution. The solution was used immediately after preparation. Tetrabutylammonium periodate (certified ACS) was purchased from Aldrich. Sodium metaperiodate was purchased from Shanghai Chemical Reagent Corporation. An aqueous solution containing $25 \mathrm{~g} \mathrm{dm}^{-3}$ sodium metaperiodate was prepared by dissolving $2 \mathrm{~g}$ of sodium metaperiodate in $80 \mathrm{~cm}^{3}$ of distilled deionized water. Although the reagent was stable, it was stored in the dark if it was to be used over an extended period of time.

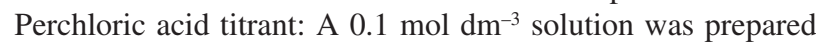
by diluting $9 \mathrm{~cm}^{3}$ of $70 \%$ perchloric acid in $1 \mathrm{dm}^{3}$ of purified dioxane. The solution was allowed to stand $24 \mathrm{~h}$ before use. The titrant was standardized potentiometrically against a KI solution.

Calibration of perchloric acid titrant: A KI solution was prepared by dissolving $17 \mathrm{~g}$ of $\mathrm{KI}$ in $1 \mathrm{dm}^{3}$ distillated water. The concentration of KI was used as the calibration solution. The concentration of perchloric acid titrant was calibrated as $0.09792 \mathrm{~mol} \mathrm{dm}^{-3}$ by the calibration solution.

\section{Procedure}

A $4 \mathrm{~g}$ solution containing the model sulfur compounds was oxidized by $150 \mathrm{mg}$ of tetrabutylammonium periodate in a 250 $\mathrm{cm}^{3}$ ground round-bottom flask, and provided a 5-times molar excess of periodate to sulfur compounds; $10 \mathrm{~cm}^{3}$ of methanol and $50 \mathrm{~cm}^{3}$ of benzene were used as the solvent. The mixture was stirred and heated under reflux for $3 \mathrm{~h}$. The solvent was evaporated under vacuum, and dioxane was added to dissolve the sulfoxides. The bottom flask was washed several times with $10 \mathrm{~cm}^{3}$ of dioxane. The flushing fluid was merged and the solution was accurately weighed. An aliquot of the solution was weighed accurately and dissolved in acetic anhydride. The solution containing sulfoxides was titrated while being stirred. Titration was performed at room temperature $\left(25^{\circ} \mathrm{C}\right)$. The electrode was equilibrated in the sample solution before titration. The potential readings were plotted as a function of the added reagent volume. The inflection point of the potentiometric curve, indicating the equivalence point, was located from the point where $\Delta^{2} E / \Delta V^{2}$ became zero. The content of aliphatic thioethers could be calculated from the
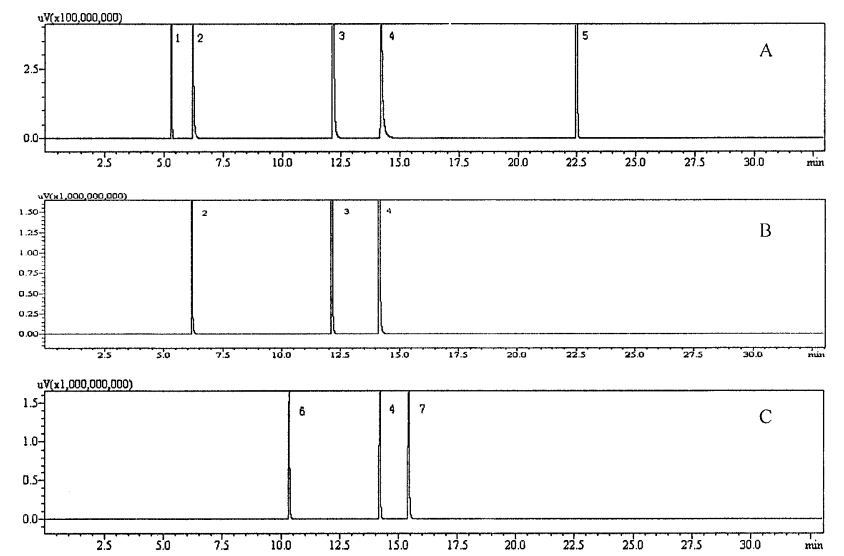

Fig. 1 FPD chromatography of the product oxidized by tetrabutylammonium periodate or sodium metaperiodate. A, model sulfur compounds; $\mathrm{B}$, the product oxidized by tetrabutylammonium periodate; $\mathrm{C}$, the product oxidized by sodium metaperiodate. Conditions: $25 \mathrm{~m} \times 0.53 \mathrm{~mm}$ glass capillary, temperature held at $80^{\circ} \mathrm{C}$ for $1 \mathrm{~min}$ and programmed from $80^{\circ} \mathrm{C}$ to $300^{\circ} \mathrm{C}$ at $10^{\circ} \mathrm{C} \mathrm{min}{ }^{-1}$ and then held for 10 min (Shimadzu GC-2010).

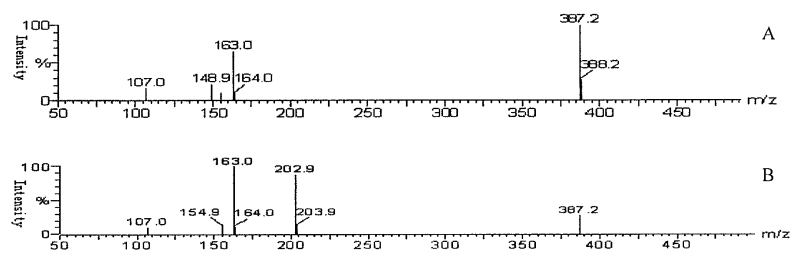

Fig. $2[\mathrm{M}+1]^{+}$mass spectra of the product oxidized by tetrabutylammonium periodate or sodium metaperiodate. A, the product oxidized by tetrabutylammonium periodate; $\mathrm{B}$, the product oxidized by sodium metaperiodate. Conditions: vaporizer temperature set at $450^{\circ} \mathrm{C}$, capillary temperature at $100^{\circ} \mathrm{C}$ and corona at $30 \mathrm{eV}$ (ZMD micromass spectrometer, Waters).

amount of perchloric acid titrant used at the inflection point.

The procedure for determining the content of total thioethers was almost the same as that mentioned above. The differences were as follows: a $4 \mathrm{~g}$ solution containing the model sulfur compounds was oxidized by $6 \mathrm{~cm}^{3}$ of aqueous sodium metaperiodate, and it provided a 10-times molar excess of periodate to sulfur compounds; $30 \mathrm{~cm}^{3}$ of acetone was used as the solvent. The reaction lasted for $30 \mathrm{~h}$ under reflux. The content of the total thioethers was calculated from the amount of titrant used, and the content of aromatic thioethers was obtained from the difference between the content of total thioethers and the content of aliphatic thioethers.

The sulfur compounds in hydrotreated base oil were determined by the same method. Two 20 -g samples of base oils were oxidized with tetrabutylammonium periodate and sodium metaperiodate, respectively. The oxidation conditions were the same as those mentioned above. The amounts of two oxidants were $0.23 \mathrm{~g}$ and $9 \mathrm{~cm}^{3}$. The contents of aliphatic and aromatic thioethers were calculated from the amounts of perchloric acid titrant.

\section{Results and Discussion}

\section{Conditions of the oxidation reaction}

Staniello and Manzocchi reported that sulfoxides were 
Table 2 Influence of a soluble oxidant on the titration

\begin{tabular}{|c|c|c|c|c|c|c|c|}
\hline \multirow[b]{2}{*}{ Sort } & \multicolumn{4}{|c|}{ Amount/g } & \multirow{2}{*}{$\begin{array}{l}\text { Theoretical } \\
\text { concentration } \\
\text { of sulfoxide } \\
\text { group/ } \mu \mathrm{g} \mathrm{g}^{-1}\end{array}$} & \multirow{2}{*}{$\begin{array}{l}\text { Amount } / \mathrm{cm}^{3} \\
\text { Titrant used }\end{array}$} & \multirow{2}{*}{$\begin{array}{l}\text { Concentration } \\
\text { of sulfoxide } \\
\text { group } \\
\text { found } / \mu g^{-1} g^{-1}\end{array}$} \\
\hline & $\begin{array}{l}\text { Dimethyl } \\
\text { sulfoxide }\end{array}$ & Dioxane & $\begin{array}{l}\text { Tetrabutyl- } \\
\text { ammonium } \\
\text { periodate }\end{array}$ & Solution & & & \\
\hline I & 0.0246 & 103 & None & 52.6103 & 146.89 & 1.627 & 145.55 \\
\hline II & 0.0375 & 102 & 0.052 & 49.7130 & 226.08 & 2.436 & 230.63 \\
\hline
\end{tabular}

Table 3 Determination of sulfur compounds in model sulfur compounds solution by potentiometric titration

\begin{tabular}{lccc}
\hline \multicolumn{1}{c}{ Analyte } & $\begin{array}{c}\text { Theoretical } \\
\text { concentration } \\
\text { of S/ } \mu \mathrm{g} \mathrm{g}^{-1}\end{array}$ & $\begin{array}{c}\text { The amount } \\
\text { of perchloric } \\
\text { acid titrant } \\
\text { used } / \mathrm{cm}^{3}\end{array}$ & $\begin{array}{c}\text { Concentration } \\
\text { of S found/ } \\
\mu \mathrm{g} \mathrm{g}^{-1}\end{array}$ \\
\hline $\begin{array}{l}\text { Aliphatic thioethers } \\
\text { Aromatic thioethers }\end{array}$ & $\begin{array}{l}220.35 \\
\text { Total thioethers }\end{array}$ & 0.289 & 226.96 \\
Thiophenes & 198.51 & 0.528 & $\begin{array}{l}187.71 \\
414.67\end{array}$ \\
\hline
\end{tabular}

selectively prepared by the oxidation of thioethers with tetrabutylammonium periodate in chloroform under heating.' $\mathrm{Xu}$ reported that tetrahydrothiophene was oxidized to the corresponding sulfoxide by tetrabutylammonium periodate under reflux, but chain aliphatic thioethers were not studied. ${ }^{10}$ It was proved that the tetrabutylammonium periodate was a good oxidant, and only aliphatic thioethers were oxidized to the corresponding sulfoxides, not to sulfones, in our experiments. The experimental results are shown in Figs. 1 and 2. In Fig. 1, the compounds of peaks 1 to 5 are butyl thioether, ethyl phenyl thioether, phenyl thioether, dibenzothiophene and dodecyl thioether, respectively.

The results oxidized by sodium metaperiodate are shown in Figs. 1 and 2. Sodium metaperiodate was found to be a good oxidant to oxidize all thioethers completely to sulfoxides without any further oxidation to sulfones. D'Alonzo reported that quantitative oxidation was accomplished under mild conditions $\left(0-25^{\circ} \mathrm{C}, 15 \mathrm{~h}\right) .^{7}$ It was different from what D'Alonzo reported, that the reaction in our experiments called for a reaction time of $30 \mathrm{~h}$ under reflux. The concentrations of sodium metaperiodate and thioethers are not critical in this procedure, because the quantitative oxidation of thioethers to sulfoxides can be accomplished over a large range of concentrations without producing of higher oxidized species, such as sulfones. Many other functional groups, such as benzyl, phenyl, and carboxyl, do not interfere, ${ }^{7}$ and dibenzothiophene can not be oxidized by sodium metaperiodate under the experiment conditions, so the method is selective.

\section{Influence of a soluble oxidant on titration}

In the experiments, solutions of two types, i.e., (I) dimethyl sulfoxide in dioxane and, (II) dimethyl sulfoxide and tetrabutylammonium periodate in dioxane, were titrated by perchloric acid titrant in acetic anhydride in order to study the influence of a soluble oxidant on the inflection point. The amounts of dimethyl sulfoxide, tetrabutylammonium periodate and dioxane are given in Table 2. The typical potentiometric curve of dimethyl sulfoxide is shown in Fig. 3. From the result of Table 2, tetrabutylammonium periodate has little effect on the titration of dimethyl sulfoxide. Because sodium

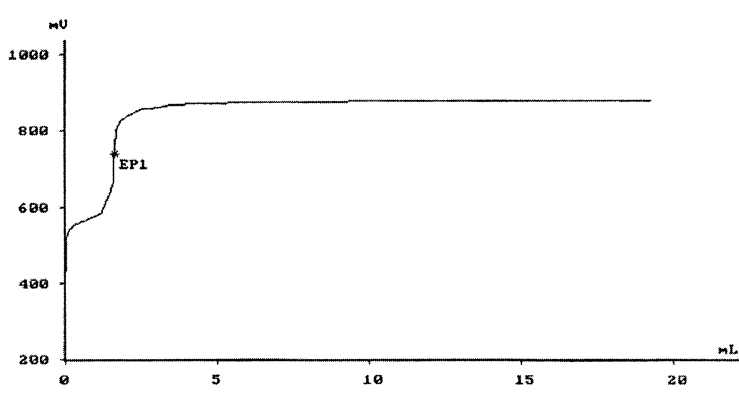

Fig. 3 Titration of dimethyl sulfoxide in solution.

metaperiodate can hardly dissolve in dioxane, it does not have any influence on the result of titration. Because thioethers and sulfones in solution exhibit no measurable basicity in acetic anhydride when they are titrated with perchloric acid, ${ }^{11}$ the thioethers and oxidants, which do not react, have no influence on the results of titration, and the oxidation products can be titrated directly without further treating.

\section{Determination of the concentrations of sulfur compounds in} model sulfur compounds and base oil

The oxidation products of model sulfur compounds were titrated respectively. The amounts of perchloric acid titrant used and the concentrations of aliphatic thioethers and total thioethers are given in Table 3. The concentration of thioethers was calculated from the concentration of the sulfoxide group, and the concentration of aromatic thioethers was obtained from the difference between the concentration of total thioethers and that of aliphatic thioethers. The concentration of thiophenes is obtained from the difference between the concentration of the total sulfur compounds (concentration prepared) and that of the total thioethers. Since the recovery of aliphatic thioethers was $103 \%$, and the recovery of aromatic thioethers was $94.56 \%$, the method for determining the aliphatic and aromatic thioethers is feasible.

In base oil, the content of nitrogen compounds was $1 \mu \mathrm{g} \mathrm{cm}^{-3}$, and it could not have any influence on the potentiometric titration. The concentration of the total sulfur compounds (including thiophenes) was determined by the ASTM D 3120 method. The method was used to determine the total content of sulfur compounds in liquid petroleum hydrocarbons by oxidative microcoulometry, and can be described as follows. A liquid sample was injected into a combustion tube maintained at about $800^{\circ} \mathrm{C}$ having a flowing stream of gas containing about $80 \%$ oxygen and $20 \%$ nitrogen. Oxidative pyrolysis converted the sulfur to sulfur dioxide, which then flowed into a titration cell where it reacted with triiodide ion present in the electrolyte. The triiodide thus consumed was coulometrically replaced and the total current required to replace it was a measure of the sulfur present in the injected sample. The concentrations of 
Table 4 Determination of sulfur compounds by potentiometric titration and ICP-AES in base oil

\begin{tabular}{lccc}
\hline \multicolumn{1}{c}{ Analyte } & $\begin{array}{c}\text { The amount } \\
\text { of perchloric } \\
\text { acid titrant } \\
\text { used } / \mathrm{cm}^{3}\end{array}$ & $\begin{array}{c}\text { Concentration } \\
\text { of S found by } \\
\text { potentiometric } \\
\text { titration } / \mu^{-1} g^{-1}\end{array}$ & $\begin{array}{c}\text { Concentration } \\
\text { of S found by } \\
\text { ICP-AES/ } \\
\mu g^{-1}\end{array}$ \\
\hline Aliphatic thioethers & 0.073 & 11.4 & 12.3 \\
Total thioethers & 0.187 & 29.3 & 30.4 \\
Thiophenes & & 80.7 & 79.6 \\
Sulfur compounds & & 110 & 110 \\
\hline
\end{tabular}

aliphatic and total thioethers were determined by the method for analyzing the model sulfur compounds and the concentrations of aromatic thiothers and thiophenes were calculated. The results are given in Table 4 . The content of thioethers was low in base oil, which accords with the oxidation method and ICPAES in our previous study.

\section{References}

1. L. James, Ind. Eng. Chem., 1958, 50, 947.

2. A. Matsunaga, U. S. Patent, 1985, 4542246.

3. J. B. Angelo, U. S. Patent, 2002, 6355850 B1.

4. R. T. Morrison and R. N. Boyd, "Organic Chemistry", 5th ed., 1987, Allyn and Bacon, Boston, 1120.

5. R. Belcher, Y. A. Gawargious, and A. M. G. Macdonald, Mikrochim. Acta, 1966, 6, 1114.

6. S. L. Leutch, J. Franklin Inst., 1945, 239, 334.

7. R. P. D'Alonzo and A. P. Carpenter, Anal. Chem., 1978, 50, 326.

8. C. B. Puchalsky, Anal. Chem., 1969, 41, 843.

9. E. Staniello and A. Manzocchi, Synthesis, 1980, 563.

10. H. Xu and Q. Shi, Acta Petrolei Sinica, 1999, 15, 28.

11. D. C. Wimer, Anal. Chem., 1958, 30, 2060. 